\title{
The analysis of cytotoxicity of an experimental preparation used for the reduction of dentin hypersensitivity
}

\author{
Marta Tanasiewicz', A, C-F , Małgorzata Skucha-Nowak1, C, E, Mirosław Gibas², E, Justyna Pawlak 3, , \\ Włodzimierz Więckiewicz ${ }^{4}, \mathrm{E}$, Anna Mertas ${ }^{5, \mathrm{~B}}$, Wojciech Król ${ }^{5, \mathrm{E}}$ \\ 1 Department of Conservative Dentistry with Endodontics, Medical University of Silesia, Bytom, Poland \\ 2 Department of Organic, Bio-organic Chemistry and Biotechnology, Technical University of Silesia, Gliwice, Poland \\ ${ }^{3}$ Dental Practice, Wrocław, Poland \\ ${ }^{4}$ Department of Dental Prosthetics, Wroclaw Medical University, Poland \\ ${ }^{5}$ Department of Microbiology and Embryology, Medical University of Silesia, Zabrze Rokitnica, Poland \\ A - research concept and design; $\mathrm{B}$ - collection and/or assembly of data; $\mathrm{C}$ - data analysis and interpretation; \\ $D$ - writing the article; $E$ - critical revision of the article; $F$ - final approval of article
}

\section{Address for correspondence \\ Marta Tanasiewicz}

E-mail: martatanasiewicz@sum.edu.pl

Funding sources

none declared

Conflict of interest

none declared

Received on September 1, 2015

Revised on November 25, 2015

Accepted on January 19, 2016

DOI

$10.17219 /$ acem/61438

Copyright

Copyright by Author(s)

This is an article distributed under the terms of the

Creative Commons Attribution Non-Commercial License

(http://creativecommons.org/licenses/by-nc-nd/4.0/)

\begin{abstract}
Background. The problem of effective treatment of dentin hypersensitivity is still valid and not fully resolved.

Objectives. The aim of the study was to evaluate the potential toxicity against body tissues of an experimental preparation which is supposed to reduce dentin hypersensitivity and to compare it to a commercial formulation Seal \& Protect (Dentsply) by means of measuring the activity of mitochondrial dehydrogenases (the MTT assay).

Material and methods. The study used an original protective formulation which is supposed to eliminate hypersensitivity of dentin. A commercial preparation Seal \& Protect (Dentsply) was used as the comparative material. Cytotoxic activity of the tested preparations (experimental and commercial) on murine lymphocyte cells CCL-1 ${ }^{\text {TM }}$ (NCTC clone 929) was determined in indirect contact with the use of the MTT test that measured the activity of the mitochondrial dehydrogenase enzyme.

Results. A comparison of the results obtained in the MTT assay for the commercial preparation Seal \& Protect (Dentsply) and the experimental formulation indicates that an experimental formulation has considerably lower cytotoxicity before polymerization, when compared to the commercial formulation, regardless of its dilution. However, after the polymerization of the commercial formulation was completed, its parameters improved significantly, especially for higher dilution values (1:10 and $1: 15)$. Results for the experimental formulation are higher, particularly for the dilution value of $1: 5$. The overall summary of the results obtained from the MTT assay for the commercial preparation Seal \& Protect (Dentsply) and the experimental formulation indicates that the experimental formulation had a significantly lower cytotoxicity before polymerization in comparison with the commercial formulation, regardless of dilution.
\end{abstract}

Conclusions. Estimating the biocompatibility of a given material is not simple, and measurement methods are rapidly evolving, as more and more is known about the interaction between dental materials and oral tissues, and also as a result of improvements in testing techniques.

Key words: cytotoxicity tests, dentine, hypersensitivity 
The problem of effectively treating dentin hypersensitivity is still valid and not fully resolved. An effective preparation used to eliminate hypersensitivity of dentin should have the following characteristics: it should be gentle to the pulp and not irritate it, quickly produce the desired therapeutic effect, be easy to apply, provide longlasting therapeutic effect, not cause pain during application, cannot discolor teeth. Despite many attempts, a formulation that meets all the expectations of dentists and provides full clinical efficacy has not yet been developed.

As new materials and preparations used in dentistry emerge and improve, assessments of their effectiveness are accompanied by research of the potentially harmful effects they may have on soft tissue of the mouth, i.e. pulp, mucosa, gum tissue. ${ }^{1-3}$ In order to analyze cell cytotoxicity of bonding systems and dental preparations based on polymer resins, tests carried out in accordance with a variety of research protocols are used for that purpose. Bacterial cultures are exposed to complex compounds or extracts of individual components that constitute these substances.

One of those tests is based on measuring mitochondrial dehydrogenase activity (the MTT assay), a part of the classic canon of tests used to assess cytotoxicity. This allows us to measure various changes reflecting the cytotoxic activity, e.g. the number of live cells, sometimes in combination with an assessment of membrane integrity, an indication of enzymatic activity associated with the metabolism of the cell, a determination of the ability of cells to divide or an indication of the total content of protein or DNA in the cell cultures. The quality of results obtained in these tests is influenced by many factors, including the stability of the cell line used, the validation of the study protocol, and the optimal choice of techniques corresponding to the needs of a given research. ${ }^{4}$
The aim of the study was to evaluate the potential toxicity against body tissues of the experimental preparation which is supposed to reduce dentin hypersensitivity and to compare it to a commercial formulation Seal \& Protect (Dentsply) by means of measuring the activity of mitochondrial dehydrogenases (the MTT assay).

\section{Material and methods}

The study used an original protective formulation which is supposed to eliminate the hypersensitivity of dentin. The formulation contains PMMAn monomer (2-(7-methyl-1,6-dioxo-2,5-dioxa-7-oktenylo) trimellitic anhydride) with adhesive properties, as well as anhydride and carboxylic functional groups which are reactive to dentin. PMMAn does not contain a potentially therapeutic fragment, so, in addition, the formula has been enriched with a therapeutic ingredient - triclosan $(\approx 5 \%)$. Methacrylate resin with a photoinitiator system constitutes $\approx 50 \%$ of the preparation. Moreover, $\approx 3 \%$ of hydroxyapatite nanopow$\operatorname{der}(\mathrm{HA})$ and $\approx 1 \%$ of potassium fluoride $(\mathrm{KF})$ was also added. Anhydrous acetone was used as the organic solvent in this formulation, constituting $\approx 31 \%$ of its total amount. A commercial preparation Seal \& Protect (Dentsply) was used as the comparative material (Table 1 ).

\section{Measurement of mitochondrial dehydrogenase activity (the MTT assay)}

Cytotoxic activity of the tested preparations (experimental and commercial) on murine lymphocyte cells CCL- $^{\mathrm{TM}}$ (NCTC clone 929) (Figs. 1, 2) was determined in indirect contact with the use of the MTT test that measured the activity of the mitochondrial dehydrogenase

Table 1. Basic chemical ingredients included in the dental preparations used to decrease hypersensitivity of dentin - commercial formulation Seal \& Protect (Dentsply) and the experimental preparation

\begin{tabular}{|c|c|c|c|c|}
\hline \multirow{2}{*}{ Functionality of the ingredient } & \multicolumn{2}{|c|}{$\begin{array}{l}\text { Commercial formulation } \\
\text { Seal \& Protect (Dentsply) }\end{array}$} & \multicolumn{2}{|c|}{$\begin{array}{l}\text { Experimental } \\
\text { preparation }\end{array}$} \\
\hline & ingredient & $\begin{array}{l}\text { mass percentage } \\
(\%)\end{array}$ & ingredient & $\begin{array}{l}\text { mass percentage } \\
(\%)\end{array}$ \\
\hline Methacrylic resin & $\begin{array}{l}\text { UDMA } \\
\text { TMPTMA }\end{array}$ & $\begin{array}{r}12.19 \\
6.51\end{array}$ & $\begin{array}{c}\text { UDMA, bis - GMA, TEGDMA } \\
(1: 1: 1)\end{array}$ & 55.40 \\
\hline Photoinitiator system & $\begin{array}{l}\mathrm{P} \text { - (N, N-dimethylamino }) \text { - ethyl } \\
\text { benzoate }\end{array}$ & 1.44 & $\begin{array}{l}\text { camphorquinone } \\
\text { DMAEMA }\end{array}$ & $\begin{array}{l}0.33 \\
1.10\end{array}$ \\
\hline Adhesive monomer & PENTA-P & 16.09 & PMMAn & 2.77 \\
\hline Solvent & acetone & 56.50 & acetone & 31.40 \\
\hline $\begin{array}{l}\text { Inorganic filler whose presence may result } \\
\text { in closure of dentinal tubules }\end{array}$ & amorphous silica & N/D & hydroxyapatite & 2.77 \\
\hline $\begin{array}{l}\text { Source of fluorine and potassium, blocks } \\
\text { dentinal tubules, removes the feeling of pain }\end{array}$ & methyl fluoride & 1.30 & KF & 0.72 \\
\hline $\begin{array}{l}\text { Antibacterial compound, reacts to } \\
\text { the following strains: Staphylococcus, } \\
\text { Streptococcus, Myctobacterium }\end{array}$ & triclosan & 5.62 & triclosan & 5.54 \\
\hline Antioxidant & $\mathrm{BHT}$ & 0.34 & - & - \\
\hline
\end{tabular}




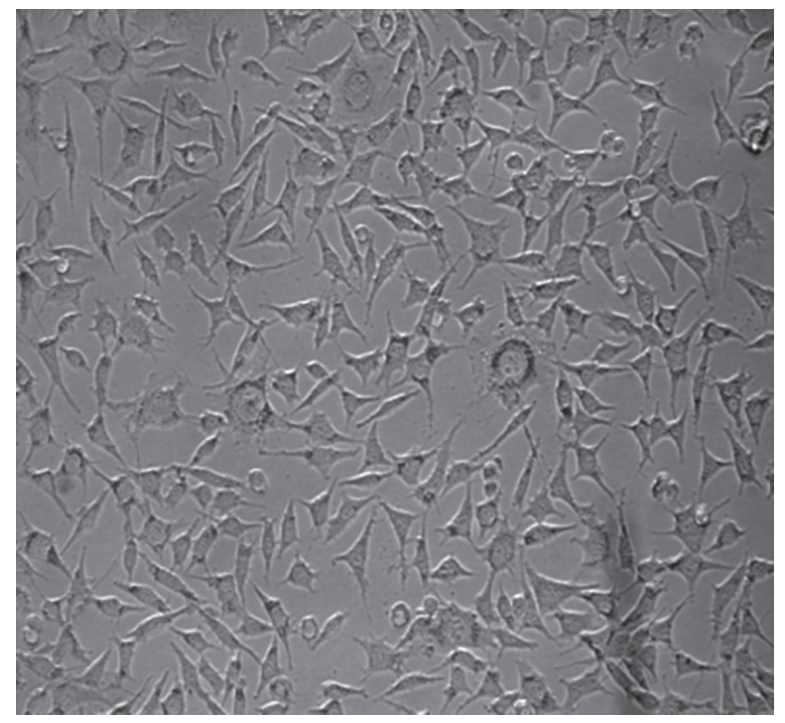

Fig. 1. Murine lymphocyte cells CCL-1 ${ }^{\mathrm{TM}}$ (NCTC clone 929) used in the tests: control group

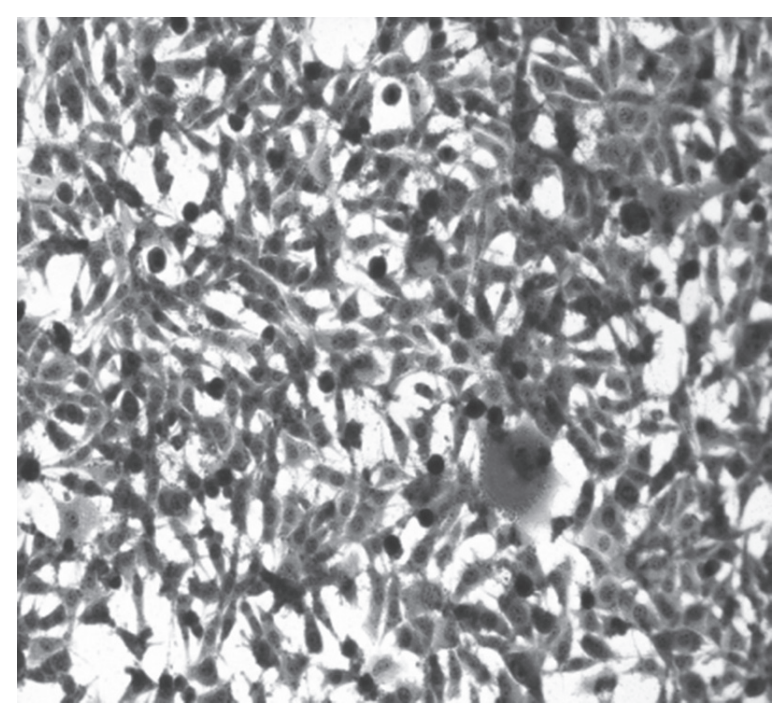

Fig. 2. Murine lymphocyte cells CCL-1 ${ }^{\mathrm{TM}}$ (NCTC clone 929) used in the tests after etching

enzyme. This test evaluates the capacity of mitochondrial succinate dehydrogenase secreted by living cells to initiate the conversion of soluble yellow tetrazolium salt (3-(4,5-dimethylthiazol-2-yl)-2,5-diphenyltetrazolium bromide) to formazan. The reaction proceeds mainly in the cytoplasm with the participation of the NADH dehydrogenase/NAD + and NADPH/NADP +. The resulting water insoluble formazan dissolves in DMSO.

\section{Methodology of tests}

The extraction of murine lymphocyte cells CCL- $1^{\mathrm{TM}}$ (NCTC clone 929) to the culture medium (DMEM) was planned for $24 \mathrm{~h}$ and 7 days. Extraction was carried out in sterile polypropylene plates (96 Well Storage Plate Flat Bottom Ltd., Non-Treated Costar-Corning Incorporated NY, 14831 USA). Prior to the test, new plates were washed twice with distilled water, dried at $50^{\circ} \mathrm{C}$ in an incubator, placed in a Petri dish and transferred to an autoclave $\left(121^{\circ} \mathrm{C} / 20 \mathrm{~min} / 2 \mathrm{~atm}\right.$ absolute pressure relative to vacuum)

\section{Extraction of non-polymerized preparations}

Twenty-five $\mathrm{mL}$ of the tested preparations (experimental and commercial) was added to each plate. In order to obtain the desired dilution, volume presented below were used: $1: 5$ dilution of $25 \mathrm{~mL}+100 \mathrm{~mL}$ of culture fluid (DMEM); $1: 10$ dilution of $25 \mathrm{~mL}+225 \mathrm{~mL}$ of culture fluid (DMEM); $1: 15$ dilution of $25 \mathrm{~mL}+350 \mathrm{~mL}$ of liquid culture medium (DMEM).

The solvents were evaporated for 3 days at $37^{\circ} \mathrm{C}$ in an incubator with the plates secured against uncontrolled evaporation of the liquid. Afterwards, the formulations were extracted. Extractions were performed in an incubator at $37^{\circ} \mathrm{C}$ with the plates secured against uncontrolled evaporation of the liquid. The following mixture volumes: $5 \mu \mathrm{L}$, $2.5 \mu \mathrm{L}$ and $1.6 \mu \mathrm{L}$ were used to obtain subsequent dilutions.

\section{Extraction of the polymerized preparations}

Twenty-five $\mathrm{mL}$ of the tested preparations (experimental and commercial) were polymerized before the extraction with a polymerization lamp halogen - HILUX 200 (600 mW/ $\mathrm{cm}^{2}$ ) - Visible Light Curing Express for dental applications.

After extracting the polymerized and unpolymerized preparations, $\mathrm{pH}$ was measured ( $\mathrm{pH}$-indicator strip) in the obtained extracts. Neutralization took place in the $\mathrm{pH}$ range of $\mathrm{pH} 7.2-7.3$.

Murine lymphocyte cells CCL- ${ }^{\mathrm{TM}}$ after treatment with the tested agents (experimental and commercial preparation) were rinsed and then added to a solution of MTT to give a final concentration of $1.1 \mathrm{mM}$ and the culture was continued for $4 \mathrm{~h}$. After this time, the cells were centrifuged, the supernatant was poured off and DMSO was added to the cells for 20 min to obtain a dissolution of formazan. The solution was collected after $20 \mathrm{~min}$ to determine the optical density $\left(\mathrm{OD}_{550}\right)$ using an automatic spectrophotometric reader at a wavelength of $550 \mathrm{~nm}$. 6-fold repetition of the measurements was used for each plate of polymerized and unpolymerized preparations. The values of mitochondrial dehydrogenase MTT, which determine the percentage of live cells for the tested formulations, were calculated based on the formula:

$$
\% \text { live cells }=[\mathrm{AB} / \mathrm{AK}] \times 100 \%
$$

Percentage of cytotoxicity (\% dead cells) was determined from the following formula:

$$
\text { cytotoxicity }(\%)=\frac{100 \%-(\mathrm{AB} \times 100 \%)}{\mathrm{AK}}
$$

where:

$\mathrm{AB}$ - absorbance of tested sample, AK - absorbance of control sample. 


\section{Statistical methods used for analysis of the results of the MTT asssay}

As part of the statistical analysis of the results of research on the measurement of mitochondrial dehydrogenase activity in the MTT assay, estimate values of basic descriptive parameters were calculated: the arithmetic mean, the expected value, standard deviation, minimum and maximum values, as well as the median and quartiles (first and third). At the same time, distribution in each analyzed case was (positively) verified in relation to the normal distribution (Shapiro-Wilk test). Thus, it became possible to use a parametric test of significance: Uniformity test of 3 means (ANOVA) - for differences due to the dilution and a test for two means from the point of view of the differences between the formulations. In justified cases, when there was a significant difference, a test of homogeneity of 3 means was supplemented with comparisons of means in pairs (each with each) using Tukey's least significant difference NIR algorithm (multivariate post-hoc analysis). Tests for two means were preceded each time with a test for two variances, which allowed the correct choice of test variant for two means. Statistical analysis of the data was performed using the program STATISTICA v. 6.0 (StatSoft/Sum license).

\section{Results}

The values obtained from measurements of the activity of mitochondrial dehydrogenase MTT which reflect the percentage of live cells for the tested preparations commercial and experimental - were converted on the assumption that the MTT assay allows for the determination of the "vitality" of the cells treated with the tested formulations. To determine the indirect cytotoxicity (\% dead cells in the MTT test) a formula to establish the CT\% value was used. The results, including the mean value and standard deviation (SD) for the experimental and commercial formulations and each dilution $(1: 5,1: 10,1: 15)$, obtained after $24 \mathrm{~h}$ and 7 days, are presented in Tables $(2,3)$ and Figs. (3-6). In the first step of the analysis, a comparison of the mean percentage of cytotoxicity in both experimental and commercial preparations obtained from the MTT assay after $24 \mathrm{~h}$ and 7 days was made. The results of the tests for 3 means, obtained according to the dilution of preparations ( $1: 5,1: 10,1: 15$ ratios), are shown in Tables 2 and 3 with indication the level of significance (p) corresponding to it. In those cases where the significance of differences was demonstrated, the arrow shows p values related to the comparison of the mean value pairs.

The next stage was a comparison of mean cytotoxicity values obtained for the experimental and commercial formulations in the MTT assay for particular dilution values of those preparations. The results of the tests for 2 means are presented in Figs. 3-6. P values are shown over the columns which reflect the compared means.

In the case of unpolymerized solutions assessed after $24 \mathrm{~h}$, higher cytotoxicity values were obtained for the commercial preparation (Seal \& Protect from Dentsply) when compared to the experimental formulation in all tested dilution ratios. The compared results showed very high statistical significance ( $\mathrm{p}<0.001$ ) (Fig. 3 ).

In the case of unpolymerized solutions assessed after 7 days, higher cytotoxicity values were obtained for the commercial preparation (Seal \& Protect from Dentsply) when compared to the experimental formulation in all tested dilution ratios. The compared results showed very high statistical significance ( $<0.001$ ) (Fig. 4).

In the case of polymerized solutions assessed after $24 \mathrm{~h}$, higher cytotoxicity values with very high statistical significance ( $<$ 0.001) were obtained for the commercial preparation (Seal \& Protect from Dentsply) after a comparison to the experimental formulation when both preparations were diluted with a ratio of $1: 5$. When the dilution ratios were $1: 10$ and $1: 15$ for both preparations, higher cytotoxicity values were obtained for the experimental formulation, in comparison to the commercial preparation (Seal \& Protect from Dentsply), which featured high statistical significance $(\mathrm{p}<0.01)$ (Fig. 5).

Table 2. The results, including the mean value and standard deviation (SD), for the experimental formulations and each dilution (1:5, $1: 10,1: 15)$, obtained after $24 \mathrm{~h}$ and 7 days

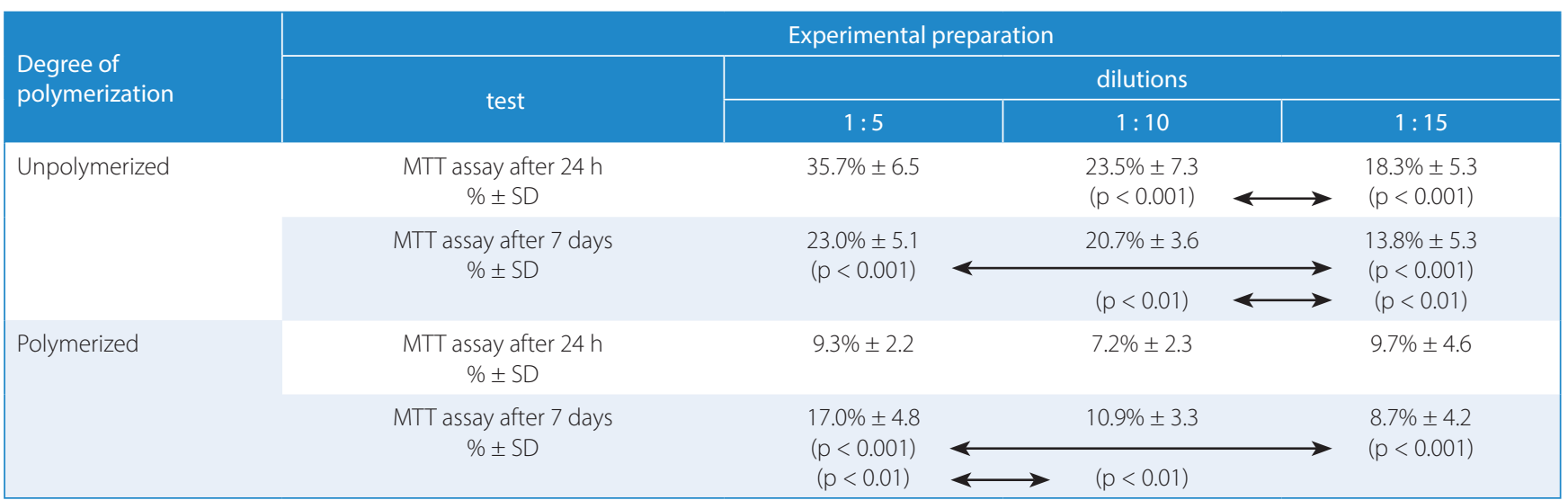


Table 3. The results, including the mean value and standard deviation (SD), for the commercial preparation Seal \& Protect (Dentsply) and each dilution (1: 5 , $1: 10,1: 15)$, obtained after $24 \mathrm{~h}$ and 7 days

\begin{tabular}{|c|c|c|c|c|c|}
\hline \multirow{3}{*}{$\begin{array}{l}\text { Degree of } \\
\text { polymerization }\end{array}$} & \multicolumn{5}{|c|}{ Commercial preparation } \\
\hline & \multirow{2}{*}{ test } & \multicolumn{4}{|c|}{ dilutions } \\
\hline & & $1: 5$ & & $1: 10$ & $1: 15$ \\
\hline \multirow[t]{2}{*}{ Unpolymerized } & $\begin{array}{c}\text { MTT assay after } 24 \mathrm{~h} \\
\% \pm \mathrm{SD}\end{array}$ & $\begin{array}{l}77.6 \% \pm 0.6 \\
(p<0.001) \\
(p<0.001)\end{array}$ & $\longleftrightarrow$ & $\begin{array}{l}71.7 \% \pm 0.9 \\
(p<0.001) \\
(p<0.001)\end{array}$ & $\begin{array}{l}\longrightarrow \quad \begin{array}{l}68.6 \% \pm 0.9 \\
(p<0.001)\end{array} \\
\longrightarrow \quad(p<0.001)\end{array}$ \\
\hline & $\begin{array}{c}\text { MTT assay after } 7 \text { days } \\
\% \pm \text { SD }\end{array}$ & $\begin{array}{c}74 \% \pm 1.5 \\
(p<0.001) \\
(p<0.01)\end{array}$ & $\longleftrightarrow$ & $\frac{68.9 \% \pm 4.2}{(p<0.01)}$ & $\begin{array}{r}68.6 \% \pm 3.2 \\
-\quad(p<0.001)\end{array}$ \\
\hline \multirow[t]{2}{*}{ Polymerized } & $\begin{array}{c}\text { MTT assay after } 24 \mathrm{~h} \\
\% \pm \mathrm{SD}\end{array}$ & $\begin{array}{c}22.6 \% \pm 8.1 \\
(p<0.001) \\
(p<0.001)\end{array}$ & $\longleftrightarrow$ & $\frac{4.0 \% \pm 2.1}{(p<0.001)}$ & $\begin{array}{l}4.4 \% \pm 1.1 \\
(p<0.001)\end{array}$ \\
\hline & $\begin{array}{c}\text { MTT assay after } 7 \text { days } \\
\% \pm \text { SD }\end{array}$ & $8.3 \% \pm 2.3$ & & $9.2 \% \pm 3.7$ & $6.1 \% \pm 2.3$ \\
\hline
\end{tabular}

In the case of polymerized solutions assessed after 7 days, higher cytotoxicity values with very high statistical significance $(\mathrm{p}<0.001)$ were obtained for the experimental formulation diluted with a ratio of $1: 5$. Other comparisons did not demonstrate any statistical significance (Fig. 6).

A comparison of the results obtained in the MTT assay for the commercial preparation Seal \& Protect (Dentsply) and the experimental formulation indicates that an experimental formulation has considerably lower cytotoxicity before polymerization, when compared to the commercial formulation, regardless of its dilution. However, after the completion of polymerization of the commercial formulation, its parameters improved significantly, especially for higher dilution values $(1: 10$ and $1: 15)$. Results for the experimental formulation are higher particularly for the dilution value of $1: 5$.

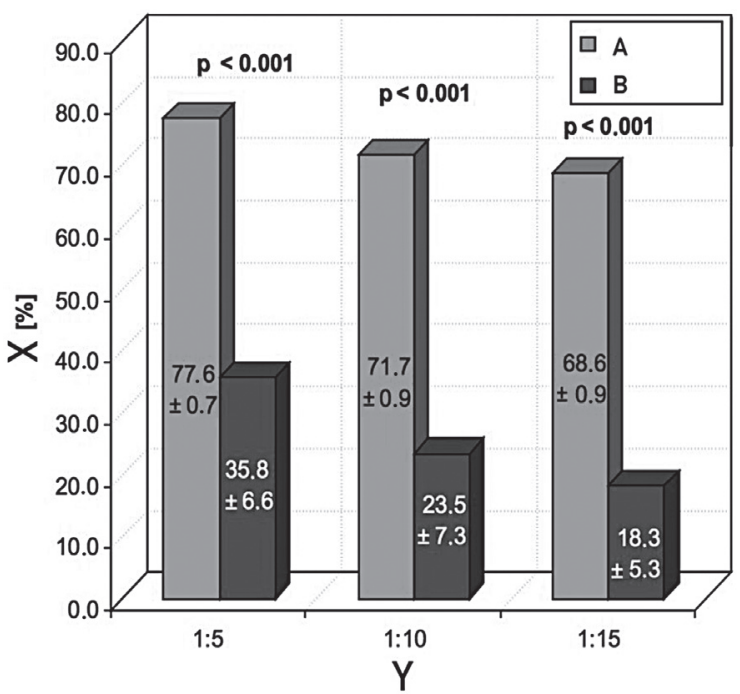

Fig. 3. A paired, dilution-related comparison of mean cytotoxicity values of the unpolymerized commercial preparation (Seal \& Protect from Dentsply) and the experimental formulation, obtained in the MTT assay after $24 \mathrm{~h}$ of testing. X - mean CT [\%], Y - dilution, A - commercial, B - experimental

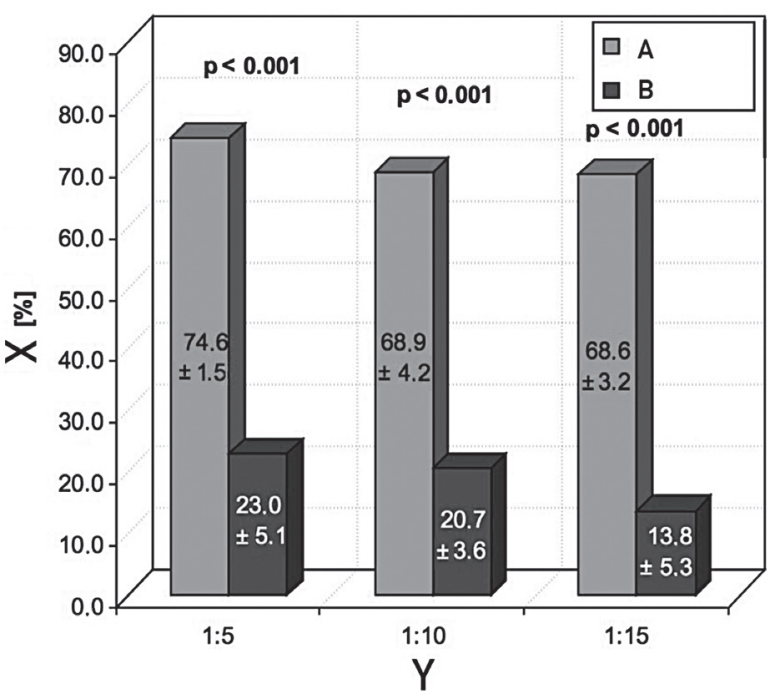

Fig. 4. A paired, dilution-related comparison of mean cytotoxicity values of the unpolymerized commercial preparation (Seal \& Protect from Dentsply) and the experimental formulation, obtained in the MTT assay after 7 days of testing. $X$ - mean CT [\%], Y -dilution, A - commercial, B - experimental

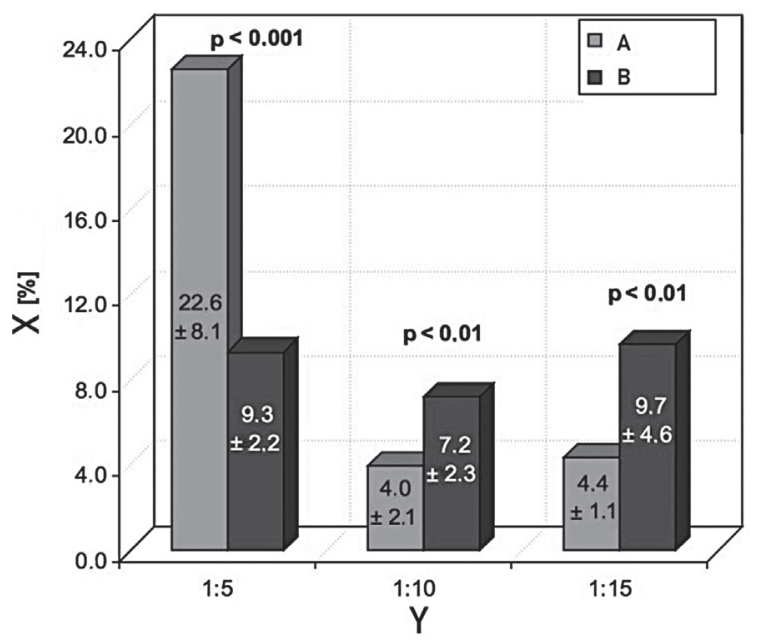

Fig. 5. A paired, dilution-related comparison of mean cytotoxicity values of the polymerized commercial preparation (Seal \& Protect from Dentsply) and the experimental formulation, obtained in the MTT assay after $24 \mathrm{~h}$ of testing. X - mean CT [\%], Y - dilution, A - commercial, B - experimental 


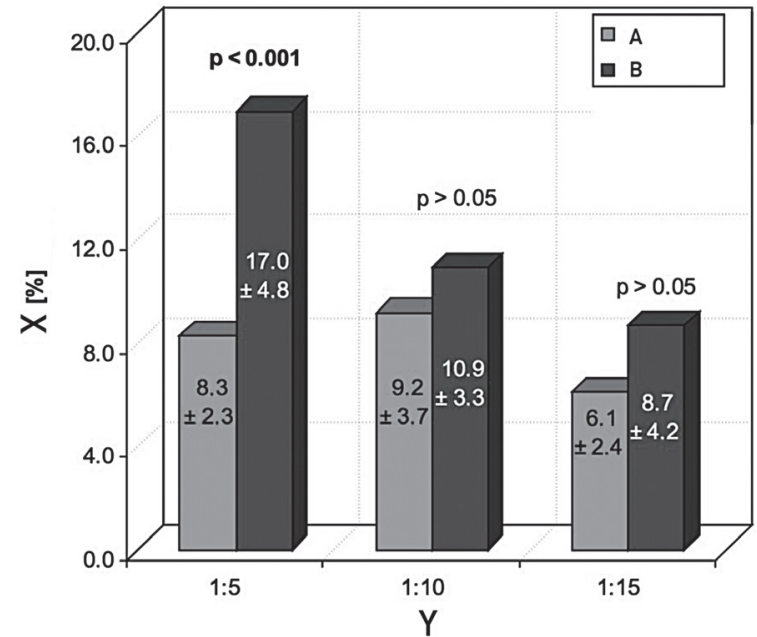

Fig. 6. A paired, dilution-related comparison of mean cytotoxicity values of the polymerized commercial preparation (Seal \& Protect from Dentsply) and the experimental formulation, obtained in the MTT assay after 7 days of testing. $\mathrm{X}$ - mean $\mathrm{CT}[\%], \mathrm{Y}$ - dilution, $\mathrm{A}$ - commercial, $\mathrm{B}$ - experimental

After polymerization, parameters of both commercial preparation Seal \& Protect (Dentsply) and experimental formulation are considerably improved. Mean cytotoxicity values are reduced, which is particularly evident for the commercial preparation Seal \& Protect (Dentsply), due to the fact that the formulation had relatively high average values of cytotoxicity before the polymerization. Reduction of the mean values of cytotoxicity of the experimental formulation is less spectacular due to the low initial value of average cytotoxicity, which it had before the polymerization.

Overall summary of the results obtained from the MTT assay for the commercial preparation Seal \& Protect (Dentsply) and the experimental formulation indicates that the experimental formulation had a significantly lower cytotoxicity before polymerization in comparison with the commercial formulation, regardless of dilution.

The process of polymerization has a positive effect on the results of cytotoxicity tests of both formulations tested. The mean cytotoxicity values of both formulations achieve a satisfactory value of less than $22.6 \% \pm 8.1$, depending on the degree of dilution and the observation time.

The experimental preparation has greater uniformity of results.

The commercial preparation Seal \& Protect (Dentsply) has a greater variation of results depending on the time of observation, dilution and used test. However, cytotoxicity values are slightly lower when compared with the experimental formulation, as seen in a test after $24 \mathrm{~h}$ at the dilution of $1: 10$ and $1: 15$.

\section{Discussion}

Cellular cytotoxicity assays have been used since the 1970 s of the $20^{\text {th }}$ century to assess the toxicity of bonding systems. Immortalized cell lines are used for that purpose, with many years of breeding cycles which allowed them to acquire traits of homogeneity. On the other hand, heterogeneous cells sampled from tissues of the oral cavity are tested, which have a short survival time and heterogeneity. The situation in vivo is generally better simulated by the second cell type. A variety of indicators showing potentially toxic components or substances full in their composition are analyzed in the assessment of cytotoxicity. These include: changes in enzyme activity, changes in cell metabolism and structure of nucleic acids, changes in cell morphology examined by light microscopy or electron SEM, the level of inhibition of cell growth and proliferation $\left(\mathrm{ED}_{50}\right.$ - effective dose inducing a $50 \%$ decrease in cell proliferation). ${ }^{2}$ Bacteria inhabiting the mouth are used in the microbiological assays. They, or their mutated forms, often have a cariogenic potential. Some authors use the strains of Streptococcus mutans to evaluate the influence of composite materials on various microbial metabolic effects. ${ }^{5}$ Genotoxicity and carcinogenicity are very important parameters to be taken into account when assessing the impact of dental materials on living organisms. Genotoxicity is assessed based on the activity of nucleic acids transformed under the influence of test substances.

During in vitro tests, genotoxicity is assessed separately for prokaryotes and eukaryotes. Amesa is an important bacterial test, while HPRT and chromosomal aberration assessment test are recommended eukaryotic tests. ${ }^{6}$ In that context, the research of Ratanasathien et al. is often cited. They independently studied the components of bonding systems and their influence on Balb/c 3T3 cell colonies. They found an increase in the cytotoxic activity over time and related to the composition of the resin, which allowed them to create a list in accordance with the severity of cytotoxicity: Bis-GMA > UDMA > $>$ TEGDMA > HEMA. ${ }^{3}$ TEGDMA appeared to be the most toxic component, which completely stopped the growth of the cell line. Two products containing EGDMA, TEGDMA demonstrated lower cytotoxicity, as well as HEMA when tested in lower concentrations. Those authors argue that 2 factors: The time of exposure and the interactions between the components of bonding resins: synergism, addition and antagonism, determine the cytotoxicity of these formulations in vivo. ${ }^{3}$

Abou Hashieh et al. studied the cytotoxic effect of 4 adhesive systems to dentin cell filbroblasts of line L29. Each product was tested using dentin samples with high and low flow. Generally, all of the analyzed systems proved to be more toxic when used in a sample of high dentin flow. These observations confirm that the dentin barrier plays a key role in immune defense against the possible toxic effect of the adhesive resin. ${ }^{7}$ This constant controversy revolves around the discussion that the cell lines are best suited to evaluate cytotoxicity. Groble et al., ${ }^{8}$ as well as Wataha ${ }^{9}$ and the previously mentioned Ratanasathien et al., ${ }^{3}$ used murine Balb/c 3T3 fibroblast cells whose sensitivity is similar to fibroblast cells of human dental pulp. 
In the available literature there are relatively few reports on the cytotoxicity of compounds that reduce hypersensitivity of dentin. ${ }^{10,11}$ Sengun et al. studied the cytotoxic effects of those preparations on the fibroblast cells of gums. The results demonstrate that cytotoxicity depends on the chemical composition and exposure time of tissue to the tested materials. ${ }^{11}$ Camps et al. found that the cytotoxic effect depends on the thickness of preserved dentin. Zero to $12 \%$ reduction of viable fibroblasts was obtained for a $0.5 \mathrm{~mm}$ thick dentin after application of self- and photopolymerizable desensibilizing compounds without their polymerization. ${ }^{10}$

Wiegand et al. investigated changes in the cytotoxic effect due to the varying thickness of dentin and used mouse fibroblasts assessed after $120 \mathrm{~min}$ from the application of materials. The cytotoxicity test was performed on the lines of immortalized mouse fibroblasts. ${ }^{12}$ Those authors also noted that the producers of compounds which reduce hypersensitivity do not give the full composition of these preparations, which makes the assessment of toxic effects of the individual components difficult to interpret. ${ }^{12}$ Disclosed or undisclosed ingredients may interact synergistically: Additively or antagonistically, and the effect on cytotoxicity may be also influenced by additional ingredients, such as triclosan, photoinitiators or glutaraldehyde. ${ }^{13}$

In the present study, a test based on measuring the mitochondrial dehydrogenase activity (MTT assay) was used. The obtained test results confirm the advantageous characteristics in relation to the relative cytotoxicity of the analyzed preparations. The polymerization process, the time of observation and the dilution favorably affect the cytotoxicity values of the two tested formulations. The experimental formulation achieved a greater stability of the results, while the commercial formulation Seal \& Protect (Dentsply) had greater variation, depending on the time of observation, dilution and assay employed, but slightly lower results of the cytotoxicity assay when compared with the experimental formulation in tests carried out after $24 \mathrm{~h}$, at the dilution of $1: 10$ and $1: 15$, and after 7 days. Mossman, who developed the MTT assay in the 1980s, reports that the level of formazan generated in the MTT assay is dependent on the number of homogeneous cells that did not undergo necrosis when affected by a toxic factor. The activated cells produce more formazan even if there is no process of proliferation. ${ }^{14}$

The next step includes a recording of data with use of colorimetric methods. The reduction of MTT to formazan occurs in all cells used in the test. ${ }^{14}$ This means that the activity of mitochondrial dehydrogenases determined in the MTT assay may be decreased due to increased mortality in the cell culture. However, at the same time, it may be increased by the activation of all cells, including non-proliferating ones. ${ }^{15}$ Among the colorimetric technique, the MTT assay is the most laborious but at the same time the most widely used quantitative method to identify the cytotoxicity of the tested substance against given cells, ${ }^{14}$ including tests of cytotoxicity made on dental materials. ${ }^{16}$ In damaged metabolically impaired or dead cells, formazan appears in smaller quantities or not at all. Changes in the levels and enzymatic activity of succinate dehydrogenase in the MTT assay are reflected in the measurement of absorbance. The intensity of the color of the solution is directly proportional to the amount of product formed and indirectly to the number of viable cells. While using the MTT assay, achievement of reliable and reproducible results requires precision at all stages of laboratory testing, with particular emphasis on the final step involving the dissolution of formazan crystals. ${ }^{9}$ Therefore, it can be assumed that the MTT assay results may be subject to errors resulting from the need to perform the experiment during the stage when the nutrient medium is exchanged with the substrate containing the analyzed compounds or when the substrate with the tested formulations are replaced by the MTT reagent. Since the cells are impaired as affected by a cytotoxic substance (in the case of those preparations used to decrease hypersensitivity of dentin), they easily detach from the substrate base. The smaller the cell adherence, the easier it is for it to be affected by an experimental error. ${ }^{15}$

Extraction of polymerized substances was tested in a number of experiments. ${ }^{17-19}$ The question if cell lines are the most suitable material for researching cytotoxicity in dental polymer materials raises continuous controversy. Some researchers prefer 3T3 mouse cells, as their cytotoxic effect has similar increase patterns as human fibroblast cell lines. The following compounds and materials have been tested: Scotchbond and SingleBond (3M ESPE), Prime \& Bond NT (Dentsply De Trey), Xeno III (Dentsply De Trey), Clearfil Protect Bond (Kuraray). Those materials contain potentially toxic ingredients in various combinations. HEMA is considered to be cytotoxic even at low concentrations $(0.5 \mathrm{mmoL} / \mathrm{L}) .{ }^{20}$ Huang and Chang, as well as Huang et al. obtained similar effects using extracts from bonding systems just after photopolymerization and after 16 weeks since their polymerization. ${ }^{18,19}$ A number of studies also analyzed binding systems and their effect on the bacterial culture in relation to: the light-curing conditions and their potentially influence on the conversion rate ${ }^{21}$ or the level of dilution. ${ }^{22}$ Non-diluted extracts had a greater lethal effect on cells than diluted extracts. ${ }^{21}$ Materials which did not undergo polymerization have a stronger cytotoxic effect than polymerized ones. ${ }^{23}$

Estimation of biocompatibility of a given material is not simple, and measurement methods are rapidly evolving, as more and more is known about the interaction between dental materials and oral tissues, and as a result of improvements in testing techniques. It is extremely important to be aware that the most accurate and effective way to evaluate biocompatibility of a new material by means of a combination of various in vitro techniques, tests on animals and clinical application tests. That con- 
cept assumes that no single test is adequate for a complete evaluation of the biocompatibility of a given material and the evaluation of biocompatibility of a new formulation is a complex, multi-stage and multi-directional process.

\section{References}

1. Ponce-Bravo S, Ledesma-Montes C, Martinez-Rivera JL, GarcesOrtiz M. Toxicity test of a dental commercial composite. J Clin Exp Dent. 2015;7(2):289-292.

2. Nocca G, Calla C, Martorana GE, et al. Effects of dental methacrylates on oxygen consumption and redox status of human pulp cells [published online on February 20 2014]. Biomed Res Int. 2014. doi: 10.1155/2014/956579.

3. Ratannasathien S, Wataha J, Hanks C, Dennison JB. Cytotoxic interactive effects of dentin bonding components on mouse fibroblasts. J Dent Res. 1995;74:1602-1609

4. Krzysztoń-Russjan J, Ksiazżek I, Anuszewska E. Porównanie użyteczności testów MTT i EZ4U stosowanych do oceny cytotoksyczności ksenobiotyków. Farm Pol. 2009;65(6):395-402.

5. Hotwani K, Thosar N, Baliga S, Bundale S, Sharma K. Antibacterial effects of hybrid tooth colored restorative materials against Streptococcus mutans: An in vitro analysis. J Conserv Dent. 2013;16(4): 319-322.

6. Bakopoulou A, Papadopoulos T, Garefis P. Molecular tixicology of substances released from resin-based dental restorative materials. Int J Mol Sci. 2009;10(9): 2861-3899.

7. Krifka S, Spagnuolo G, Schmalz G, Schweikl H. A review of adaptive mechanisms in cell responses towards oxidative stresses caused by dental resin monomers. Biomaterials. 2013;34(19):4555-4563.

8. Abou Hashieh I, Franquin IC, Cosset A, Dejou I, Camps I. Relationship between dentine hydraulic conductance and the cytotoxicity of four dentine bonding resins in vitro. J Dent. 1998;26:473-477.

9. Groble SR, Oliver A, Moodley D, van Dyk Kotze J. Cytotoxicity of recent dentin bonding agents on Mouse fibroblast cells. Quintessence Int. 2008;39:511-516.

10. Wataha JC. Cytotoxicity of componenets of resin and other restorative materials. J Oral Rehab. 1994;21:453-462.

11. Camps J, Aboutt I, van Meerebeek B, Franquin JC. Efficiency and cytotoxicity of resin-based desesitizing agents. Am J Dent. 2002;15:300-304.
12. Sengun A, Buyukbas S, Hakki SS. Cytotoxic effects of dental desensitisers on human gingival fibroblast. J Biomed Mater Res B Appl Biomater. 2006;78:131-137.

13. Wiegand A, Buchholz K, Werner C, Attin T. In vitro cytotoxicity of different desensitizers under simulated pulpal flow conditio. J Adhes Dent. 2008;10:227-232.

14. Fujisawa S, Kadoma Y. Prediction of the reduced glutathione (GSH) reactivity of dental methacrylate monomers using NMR spectra - Relationship between toxicity and GSH reactivity. Dent Mater J. 2009;28(6):722-729.

15. Mossman T. Rapid colorimetric assay for cellular growth and survival: Application for proliferation and cytotoxicity assays. J Immunol Meth. 1983;65:55-63.

16. Buonocore D, Grosini M, Giardina S, et al. Bioavailability study of an innovative orobuccal formulation of glutathione [published online on November 16 2016]. Oxid Med Cell Longev. 2016. doi: $10.1155 / 2016 / 3286365$.

17. Olteanu D, Filip A, Socaci C, et al. Cytotoxicity assessment of graphene-based nanomaterials on human dental follicle stem cells. Colloids Surf B Biointerfaces. 2015;21:791-798.

18. Franz A, Konig F, Lucas T, Watts DC, Schelde A. Cytotoxic effects of dental bonding substances as a function of degree of conversion. Dent Mater. 2009;25:232-239.

19. Huang FM, Chang YC. Cytotoxicity of dentin-bonding agents on human pulp cell in vitro. Int Endod J. 2002;35:905-909.

20. Huang FM, Chou MY, Chang YC. Dentin bonding agents induce c-fos and c-jun protooncogenes expression in human gingival fibroblasts. Biomater. 2003;24: 157-163.

21. Koulaouzidou EA, Papazisis KT, Yiannaki E, Palagbias G, Helvatjoglu-Antoniades M. Effects of dentin bodning agents on the cell cycle of fibroblastis. I Enodod. 2009;35:275-279.

22. Barbosa MO, de Carvalho RV, Demarco FF, et al. Experimental selfetching HEMA-free adhesive systems: Cytotoxicity and degree of conversion. J Mater Sci Mater Med. 2015;26(1):5370-5375.

23. Oliveira DC, Silva CB, Muniz BV, Volpato MC, Costa AR, Sinhoreti MA. Effect of 4-(N,N-dimethylamino)phenethyl alcohol on degree of conversion and cytotoxicity of photo-polymerized CQbased resin composites. Braz Dent J. 2014;25(6):538-542.

24. Tsitrou E, Kelogrigoris $S$, Koulaouzidou E, Antoniades-Halvatjoglou M, Koliniotou-Koumpia E, van Noort R. Effect of extraction media and storage time on the elution of monomers from four contemporary resin composite materials. Toxicol Int. 2014;21(1):89-95. 